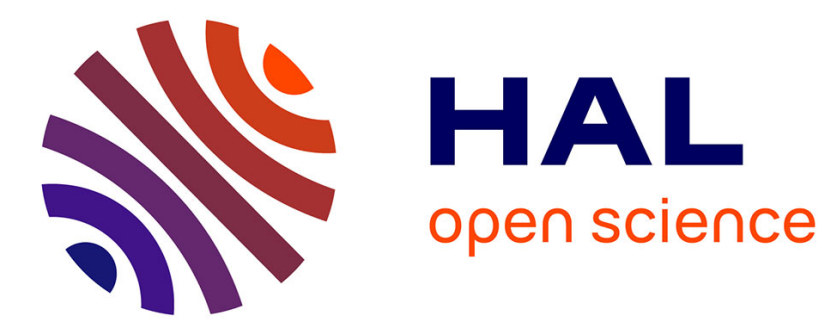

\title{
Plant biology in space
}

G. Ruyters, F. Spiero, Valérie Legué, K. Palme

\section{- To cite this version:}

G. Ruyters, F. Spiero, Valérie Legué, K. Palme. Plant biology in space. Plant Biology, 2014, 16 (1), pp.1-3. 10.1111/plb.12129. hal-01189957

\section{HAL Id: hal-01189957 \\ https://hal.science/hal-01189957}

Submitted on 1 Sep 2015

HAL is a multi-disciplinary open access archive for the deposit and dissemination of scientific research documents, whether they are published or not. The documents may come from teaching and research institutions in France or abroad, or from public or private research centers.
L'archive ouverte pluridisciplinaire HAL, est destinée au dépôt et à la diffusion de documents scientifiques de niveau recherche, publiés ou non, émanant des établissements d'enseignement et de recherche français ou étrangers, des laboratoires publics ou privés. 


\section{Plant biology in space}

In August 2012, more than 60 invited scientists and representatives of space agencies from different continents, nationalities and disciplines attended the international workshop on 'Plant Biology Research in Space', held at the University of Freiburg, Germany. This workshop - jointly organised by the French and German space agencies, CNES and DLR - was embedded as satellite symposium into the Plant Biology Congress 2012, held by FESPB and EPSO, the two leading European organisations involved in plant research. Using this setup, it was also hoped that scientists from the so-called nonspace community would be attracted to the specific topic of plant biology in space. This idea proved very successful: more than 600 participants attended - for instance - the plenary lecture from Stan Roux on 'New insights in plant biology gained from space research'.

The 'Plant Biology in Space' workshop was one in a series of symposia, initiated in 1995 by the International Space Life Sciences Working Group (ISLSWG) of leading space agencies from around the globe. The main goal of these workshops is to review progress in a specific research area and to identify open questions for future space and accompanying ground-based research, thereby stimulating international cooperation. Interestingly, the first plant biology workshop was also held in Germany, in 1996. Since then, more than 20 workshops have been organised by ISLSWG, ranging from molecular, cell, plant and radiation biology via muscle, bone and neurovestibular physiology, to behaviour and performance of humans in space. The results of these workshops have been published in high-ranking scientific journals, often as supplements or special issues.

The ISLSWG itself was established in 1989; at that time, representatives of the leading life sciences programmes of six space agencies agreed to form a special working group with two overall goals, namely, to strengthen space research by increased coordination and cooperation as well as to enhance the exchange of knowledge and information. The six space agencies were NASA (United States), ESA (Europe), CNES (France), CSA (Canada), DLR (Germany) and JAXA (Japan). Since then, also the space agencies of Italy (ASI) and of Ukraine (NSAU) joined the group. Through the establishment of ISLSWG and the development and implementation of its strategic plan, cooperation among space agencies in the field of life sciences, which had happened for more than 20 years on a more case-by-case basis, was placed on official solid ground.

Since its foundation more than 20 years ago, the ISLSWG has achieved a lot: joint Spacelab/Shuttle missions were realized; in terms of human physiology research, also bed rest and isolation studies were jointly conducted. The ISLSWG coordinated the development of experiment facilities, e.g. for the International Space Station (ISS). Also, the use of the ISS for life science research was - and still is - coordinated with great efficiency. Up to now there have been six ILSRAs (International Space Life Sciences Research Announcements). Experiment proposals have been recruited for ISS research also in plant biology, jointly peer reviewed by international review teams and selected for implementation on ISS. Moreover, the seventh ILSRA is currently open for proposal submission until end of March 2014.

This special supplement of Plant Biology presents the outcome of the Freiburg Plant Biology workshop, focusing on the fundamental role that gravity plays in plant growth, development and orientation. The reader will find ten scientific reviews and 13 research papers from a group of experts, most of them involved in space biology research. The supplement starts with an acute view of accomplishments achieved and recommendations for future research for plant biology in space. Here, also an attempt is undertaken to analyse whether and how the recommendations of the 1996 ISLSWG Plant Biology workshop have been followed and which of the scientific questions - prioritised at that time - have been answered in the meantime (Ruyters \& Braun 2014). Also as a kind of recommendation for future work, Kiss (2014) proposed exciting perspectives in the context of Mars and Moon exploration.

The contributions of the supplement focus basically on three different topics: plant growth and physiology, with special attention given to gravitropism; plant molecular biology; and the role of plants in bioregenerative life support systems (BLSS). The gravitropic response pathway as such can be divided into sequential steps: (i) perception of the signal; (ii) signal transduction leading to the redistribution of auxin, and finally; (iii) the gravitropic curvature response.

Kordyum (2014) provides a short overview on the effects of real and simulated microgravity on cell components, including statolith positioning, mitochondria, tubulin and the endoplasmic reticulum. Although significant progress has been made in identifying stimulus-responsive elements, the nature of the sensors remains elusive. Iida et al. (2014) summarise their work on a group of mechanosensitive channels in Arabidopsis, named MCA1 and MCA2, and their putative role in gravity sensing in Arabidopsis. Tatsumi et al. (2014) describe recent progress in mechanosensitive channels controlled by the actin cytoskeleton. The involvement of the actin cytoskeleton in gravity perception is further investigated in plant cells. Using imaging tools, Grolig et al. (2014) report on the role of actin in organelle movement in the sporangiophore of the zygomycete Phycomyces blakesleeanus.

Auxin transport is an essential component of the signalling pathway of root and shoot gravitropism. Progress in this area is highlighted in the paper from Geisler et al. (2014), describing approaches used for the analysis of auxin redistribution and quantification of auxin fluxes. The report of Ueda et al. (2014) complements this view by examining the relationship between polar auxin transport and graviresponse in the context of microgravity. A comprehensive analysis of global gene expression of floral buds reveals that hypergravity substantially changes expression of genes involved in the biosynthesis of 
phytohormones such as abscisic acid and auxin (Tamaoki et al. 2014).

The effects of gravity on plant developmental processes are reviewed in Herranz \& Medina (2014). They studied microgravity effects on cell proliferation within the root meristem. Using parabolic flights, the studies of Hausmann et al. (2014) and Aubry-Hivet et al. (2014) reported changes in gene and protein expression in $A$. thaliana cells and fundamental changes in metabolic pathways, respectively. The interesting report from Hoson et al. (2014) supports the concept that microtubules are important players in mediating gravity resistance in Arabidopsis. Furthermore, Nakashima et al. (2014) provide evidence that actin might also be an important modulator of root growth in space, while Scherer \& Pietrzyk (2014) report on root coiling in Arabidopsis.

Although in most of the research described A. thaliana is used as model species, some other model organisms are also discussed. Galland (2014) and Göttig \& Galland (2014) use the sporangiophore of $P$. blakesleeanus to investigate fungal graviperception and graviresponses. Analyses of spores of the fern Ceratopteris richardii reveal the gravity-affected expression of a PM-type $\mathrm{Ca}^{2+}$ ATPase (Bushart et al. 2014). Scherer \& Quader (2014) show a transient increase of endocytosis in tobacco pollen tubes in microgravity. Finally, using Euglena gracilis, Nasir et al. (2014) demonstrate changes in expression of stressrelated genes in microgravity, confirming results from higher plants.

Space experiments are certainly the best method for studying the effects of changed gravity conditions on plant developmental processes; however, also the considerable impact of radiation on organisms must be considered when going into space. Arena et al. (2014) demonstrate in Phaseolus vulgaris how leaf development and growth biochemically respond to ionising radiation. Similar results obtained by De Micco et al. (2014b) $P$. vulgaris leaves.

Although we are aware that seed-to-seed cycles can be achieved, the review from De Micco et al. (2014a) highlights the consequences for crop productivity. Generally supporting this view, Paradiso et al. (2014) provide a state-of-the-art summary of soybean cultivation in the bioregenerative show the effect of X-ray irradiation on the anatomy of mature some negative effects of space conditions on plant growth and

ecosystem MELISSA (Micro-Ecological Life-Support System Alternative). These papers underline the crucial importance of the development of new technologies for BLSS and the importance of analysing all growth and reproductive phases of the plant life cycle in order to optimise utilisation of resources in plant-based BLSS.

We feel confident that the contributions in the present supplement will provide interesting information on plant biology research in space and useful guidelines for scientists around the world for future research in this fascinating field. As has been convincingly shown in the past, results of these activities are not only important in the context of space research, but also contribute to answering fundamental questions in the area of plant biology, e.g. on plant growth and development as well as on signal transduction in plants.

Finally, the editors and the space agency representatives thank the authors for their contributions, the many dedicated reviewers for helping to improve and strengthen the papers published in this supplement, as well as the workshop session chairs and Prof. Volkmann (University of Bonn) for providing valuable inputs for the analysis of accomplishments and future recommendations for research in plant biology in space.

G. Ruyters
Life Sciences Program, DLR (German Space Administration),
Bonn, Germany
E-mail: guenter.ruyters@dlr.de
F. Spiero
Human Spaceflight and Exploration, CNES (French Space
Agency), Paris, France
E-mail: francois.spiero@cnes.fr
V. Legué
Clermont Université, Université de Lorraine, Aubiere, France
E-mail: valerie.legue@univ-lorraine.fr
K. Palme
Albert-Ludwigs-Universität, Molecular Plant Physiology,
Freiburg, Germany
E-mail: klaus.palme@biologie.uni-freiburg.de

\section{REFERENCES}

Arena C., De Micco V., De Maio A. (2014) Growth alteration and leaf biochemical responses in Phaseolus vulgaris exposed to different doses of ionising radiation. Plant Biology, 16 (Suppl. 1), 194-202.

Aubry-Hivet D., Nziengui H., Rapp K., Oliveira O., Paponov I.A., Li Y., Hauslage J., Vagt N., Braun M., Ditengou F.A., Dovzhenko A., Palme K. (2014) Analysis of gene expression during parabolic flights reveals distinct early gravity responses in Arabidopsis roots. Plant Biology, 16 (Suppl. 1), 129-141.

Bushart T., Clark G., Roux S.J. (2014) Structure and function of CrACAl, the major PM-type $\mathrm{Ca}^{2+}$ ATPase expressed at the peak of the gravity-directed trans-cell calcium current in spores of the fern Ceratopteris richardii. Plant Biology, 16 (Suppl. 1), 151-157.

De Micco V., De Pascale S., Paradiso R., Aronne G. (2014a) Microgravity effects on different stages of higher plant life cycle and completion of the seed-toseed cycle. Plant Biology, 16 (Suppl. 1), 31-38.

De Micco V., Arena C., Aronne G. (2014b) Anatomical alterations of Phaseolus vulgaris L. mature leaves irradiated with X-rays. Plant Biology, 16 (Suppl. 1), 187-193.

Galland P. (2014) The sporangiophore of Phycomyces gravireception and graviresponses. Plant Biology, 16 (Suppl. 1), 58-68.

Geisler M., Wang B., Zhu J. (2014) Auxin transport during root gravitropism: transporters and techniques. Plant Biology, 16 (Suppl. 1), 50-57.

Göttig M., Galland P. (2014) Gravitropism in Phycomyces: violation of the so-called resultant law evidence for two response components. Plant Biology, 16 (Suppl. 1), 158-166.

Grolig F., Moch J., Schneider A., Galland P. (2014) Actin cytoskeleton and organelle movement in the sporangiophore of the zygomycete Phycomyces blakesleeanus. Plant Biology, 16 (Suppl. 1), 167-178. blakesleeanus: a tool to investigate fungal
Hausmann N., Fengler S., Hennig A., Franz-Wachtel M., Hampp R., Neef M. (2014) Cytosolic calcium, hydrogen peroxide and related gene expression and protein modulation in Arabidopsis thaliana cell cultures respond immediately to altered gravitation: parabolic flight data. Plant Biology, 16 (Suppl. 1), 120-128.

Herranz R., Medina F.J. (2014) Cell proliferation and plant development under novel altered gravity environments. Plant Biology, 16 (Suppl. 1), 23-30.

Hoson T., Soga K., Wakabayashi K., Hashimoto T., Karahara I., Yano S., Taniqaki F., Shimazu T., Kasahara H., Masuda D., Kamisaka S. (2014) Growth stimulation in inflorescences of an Arabidopsis tubulin mutant under microgravity conditions in space. Plant Biology, 16 (Suppl. 1), 91-96.

Iida H., Furuichi T., Nakano M., Toyota M., Sokabe M., Tatsumi H. (2014) New candidates for mechano-sensititve channels potentially involved in gravity sensing in Arabidopsis thaliana. Plant Biology, 16 (Suppl. 1), 39-42. 
Kiss J.Z. (2014) Plant biology in reduced gravity on the Moon and Mars. Plant Biology, 16 (Suppl. 1), 12-17. Kordyum E. (2014) Plant cell gravisensitivity and adaptation to microgravity. Plant Biology, 16 (Suppl. 1), 79-90.

Nakashima J., Liao F., Sparks J.A., Tang Y., Blancaflor E.B. (2014) The actin cytoskeleton is a suppressor of the endogenous skewing behaviour of Arabidopsis primary roots in microgravity. Plant Biology, 16 (Suppl. 1), 142-150.

Nasir A., Strauch S.M., Becker I., Sperling A., Schuster M., Richter P.R., Weißkopf M., Ntefidou M., Daiker V., YanJun A., Xiao Yan L., Yong Ding L., Lebert M. (2014). The influence of microgravity on Euglena gracilis as studied on Shenzhou 8. Plant Biology, 16 (Suppl. 1), 113-119.
Paradiso R., De Micco V., Buonomo R., Aronne G., Barbieri G., De Pascale S. (2014) Soilless cultivation of soybean for Bioregenerative Life Support Systems (BLSSs): a literature review and the experience of the MELiSSA project - food characterisation Phase I. Plant Biology, 16 (Suppl. 1), 69-78.

Ruyters G., Braun M. (2014) Plant biology in space: recent accomplishments and recommendations for future research. Plant Biology, 16 (Suppl. 1), 4-11.

Scherer G.F.E., Pietrzyk P. (2014) Gravity-dependent differentiation and root coils in Arabidosis thaliano wild type and phospholipase-A-I knock-down mutant grown on the International Space Station. Plant Biology, 16 (Suppl. 1), 97-106.

Scherer G.F.E., Quader H. (2014) Increased endocytosis of fluorescent phospholipid in tobacco pollen in microgravity and inhibition by verapamil. Plant Biology, 16 (Suppl. 1), 107-112.

Tamaoki D., Karahara I., Nishiuchi T., Wakasugi T. Yamada K., Kamisaka S. (2014). Effects of hypergravity stimulus on global gene expression during reproductive growth in Arabidopsis. Plant Biology, 16 (Suppl. 1), 179-186.

Tatsumi H., Furuichi T., Nakano M., Toyota M., Hayakawa K., Sokabe M., Iida H. (2014). Mechanosensitive channels are activated by stress in the actin stress fibres, and could be involved in gravity sensing in plants. Plant Biology, 16 (Suppl. 1), 18-22.

Ueda J., Miyamoto K., Uheda E., Oka M., Yano S., Higashibata A., Ishioka N. (2014) Close relationships between polar auxin transport and graviresponse in plants. Plant Biology, 16 (Suppl. 1), 43-49. 